BRIEF REPORT

\title{
ROTATORY MALUNION OF THE LATERAL MALLEOLUS CORRECTED BY OSTEOTOMY
}

\author{
R. T. AUSTIN
}

A 37 -year-old man gave a history of instability of the right ankle since an untreated injury at the age of 12 . Examination showed excessive lateral movement of the talus within the mortice, but there was a full range of movement at the ankle, subtalar and midtarsal joints. Radiographs showed widening of the ankle mortice with lateral talar shift suggestive of old rupture of the medial ligament (Fig. 1). Comparison with views of the left ankle showed no shortening or angulation of the lateral malleolus, but stress views confirmed abnormal lateral movement of the talus without diastasis of the inferior tibiofibular joint. The diagnosis was considered to be chronic rupture of the medial ligament with a lateral rotation deformity of the lateral malleolus.

Operation. A medial incision was made to clear degenerative fibrous tissue from the medial joint space. Through a lateral incision a transverse osteotomy of the fibula was performed and the distal fragment rotated $15^{\circ}$ medially, pivoting on the posterior cortex. This was seen to close the medial gap. The position was held with two small plates and a below-knee non-weight bearing plaster was worn for eight weeks. One year later, after plate removal, the ankle was stable (Fig. 2) and a full range of movement had been regained.

Discussion. Lateral talar shift within a wide mortice can result from various combinations of injury. Rupture of the medial ligament is necessary to allow talar displacement, but lateral support may be lost after a displaced oblique fracture of the lateral malleolus or with diastasis of the inferior tibiofibular joint. These may be combined as "fracture diastasis" (Colton 1968). Shortening of the malleolus after a high fibular fracture also allows talar shift because the oblique articular surface of the malleolus is no longer closely applied to the talus (Colton 1971).

Oblique fractures or epiphyseal injuries of the lower fibula are uncommon in childhood. Spiegel, Cooperman and Laros (1978) reviewed 25 epiphyseal injuries but made no comment on rotatory deformity or associated rupture of the medial ligament. Lengthening of the fibula to correct shortening which had allowed lateral talar shift was described by Hughes (1976), who had 22 good or

R. T. Austin, FRCS Ed, Consultant Orthopaedic Surgeon The Royal Infirmary, Leicester LEl 5WW, England.

(C) 1987 British Editorial Society of Bone and Joint Surgery $0301-620 \mathrm{X} / 87 / 3 \mathrm{R} 21 \$ 2.00$

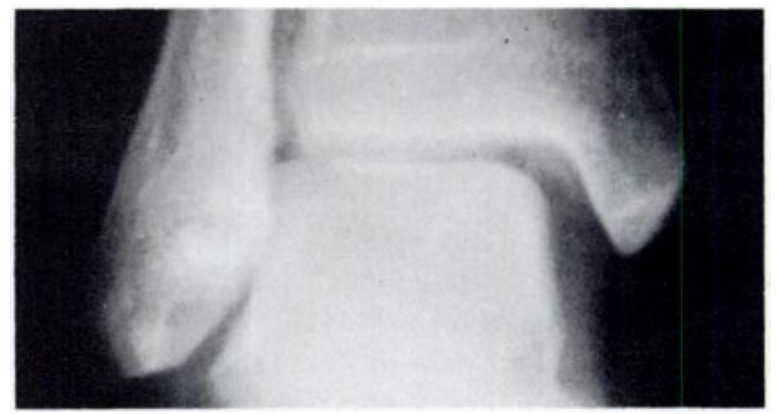

Fig. 1

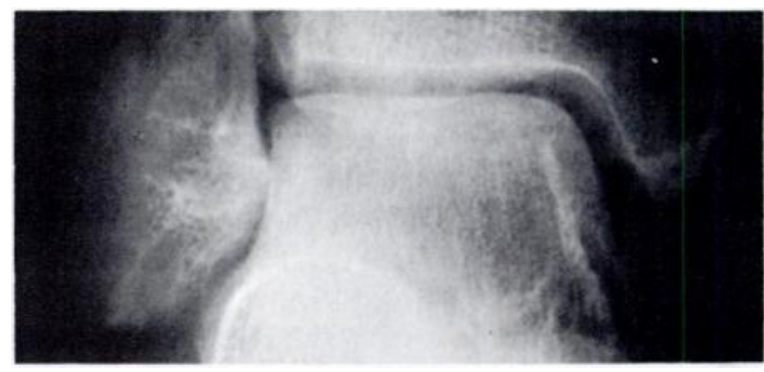

Fig. 2

very good results in 25 cases.

The precise deformity of the lateral malleolus was uncertain in this case, since comparative radiographs provided no evidence of shortening, angulation or diastasis. However, the talus appeared to overlap the lateral malleolus: since the fibula lies in a posterior position, this must have resulted from an external rotation deformity. The correction and the good clinical result gained by the rotation osteotomy confirm this diagnosis.

I would like to thank the Department of Medical Illustration of the Leicester Royal Infirmary for the photographs and Miss Helen Barradell for the typescript.

\section{REFERENCES}

Colton CL. Fracture-diastasis of the inferior tibio-fibular joint. $J$ Bone Joint Surg [Br] 1968:50-B:830-5.

Colton CL. The treatment of Dupuytren's fracture-dislocation of the ankle. J Bone Joint Surg [Br] 1971;53-B:63-71.

Hughes JL. Corrective osteotomies of the fibula after defectively healed ankle fractures. J Bone Joint Surg [Am] 1976;58-A:728.

Spiegel PG, Cooperman DR, Laros GS. Epiphyseal fractures of the distal ends of the tibia and fibula: a retrospective study of twohundred and thirty-seven cases in children. J Bone Joint Surg [Am] 1978;60-A :1046-50. 